\title{
Multiband and Low-Profile Frequency Reconfigurable Microstrip Patch Antenna Design Using Single PIN diode for WiFi/GPS applications
}

\section{Shobhit K. Patel}

Marwadi University

sana ben khalifa ( $\square$ sanaa.benkhalifa@gmail.com )

Qassim University College of Science and Arts in Alrass https://orcid.org/0000-0001-5541-9667

saleh chebaane

University of Hail College of Sciences

Sunil Lavadiya

Marwadi University

Yagnesh Parmar

Marwadi University

Juveriya Parmar

Marwadi University

\section{Research Article}

Keywords: Multiband frequency tunability, microstrip patch antenna, FR-4, PIN diode

Posted Date: September 7th, 2021

DOl: https://doi.org/10.21203/rs.3.rs-872444/v1

License: (9) (i) This work is licensed under a Creative Commons Attribution 4.0 International License.

Read Full License 


\title{
Multiband and Low-Profile Frequency Reconfigurable Microstrip Patch Antenna Design Using Single PIN diode for WiFi/GPS applications
}

\author{
Shobhit K. Patel ${ }^{1,2}$, Sana ben Khalifa ${ }^{3,4, *}$, Saleh Chebaane ${ }^{5,6}$, \\ Sunil Lavadiya ${ }^{2,7}$, Yagnesh Parmar $^{2}$, Juveriya Parmar ${ }^{8}$ \\ ${ }^{1}$ Department of Computer Engineering, Marwadi University, Rajkot-360003, Gujarat, India. \\ ${ }^{2}$ Department of Electronics and Communication, Marwadi University, Rajkot-360003, Gujarat, India. \\ ${ }^{3}$ Physics Department, College of Science \& Arts at Ar-Rass, Qassim University,P.O.Box 53, ArRass \\ 51921,Saudi Arabia \\ ${ }^{4}$ Laboratory of Energy and Materials (LabEM), ESSTHS, University of Sousse, 4011 H.Sousse, Tunisia \\ ${ }^{5}$ Physics Department, College of Science, University of Ha'il, P.O.Box 2440, Ha'il, Saudi Arabia \\ ${ }^{6}$ Laboratoire d'électronique et micro-électronique (LAB-IT06) Faculté des Sciences de Monastir, \\ Monastir, Tunisia \\ ${ }^{7}$ Department of information and communication engineering, Marwadi University, Rajkot-360003, \\ Gujarat, India. \\ ${ }^{8}$ Department of Physics, Marwadi University, Rajkot-360003, Gujarat, India. \\ *Corresponding Author: Sana ben Khalifa \\ Sanaa.benkhalifa@gmail.com
}

\begin{abstract}
:
The novel and simple approach for achieving frequency tunability is presented. The frequency tunability is achieved using a single PIN diode. PIN diode located on the upper side of the structure to reduces the biasing complexity. The superstrate structure along with the corner truncation helps for enhancing the performance parameters, as well the location of feed and slot of the patch is varied for locating best performing points. This design provides the multiband frequency tunability behavior with the maximum frequency tunability of $100 \mathrm{MHz}$. The design provides the minimum reflectance coefficient of $-22.56 \mathrm{~dB}$, the directivity of $6.98 \mathrm{~dB}$, the total gain of $3.683 \mathrm{~dB}$, normalized directivity of $88^{0}$ using the low profile (FR-4) substrate which helps for the cost reduction and mass production. The simulation is carried out using the HFSS tool. The fabrication of the proposed design is also presented. This design suitable for Wifi, GPS, and many more wireless communication applications.
\end{abstract}

Keywords: Multiband frequency tunability, microstrip patch antenna, FR-4, PIN diode. 


\section{Introduction:}

Reconfiguration of frequency in antennas is highly required now a day to cover a wide range of portable wireless applications [1][2]. The antenna design requires high gain, multiband and tunable applications to meet the current demand of wireless communications devices [3]. Compact antenna design is also very crucial as the size of the portable wireless devices is going smaller and smaller [6][7]. Metamaterials are the one option that can be used to solve the demand of current antenna designs [8]. The use of metamaterials can improve the gain, bandwidth, and can also reduce the size of existing antenna designs [9]. Reconfiguration of frequency and radiation pattern and polarization can be attained by incorporating RF switches in an antenna [10]. PIN diodes are one of the switches which can be used to achieve reconfiguration in antenna design [11].

Metamaterials are artificially engineered materials. It possesses great electromagnetic properties, which are not available in nature [12]. Metamaterials differentiate antennas on basis of meta-resonators and metamaterial loading [13] for metamaterials, Metasurfaces (2D planar structure) are used as reflectors or lens in an antenna which is useful for the design of radiofrequency device miniaturization[14], metamaterial-based antenna possesses good radiation efficiency for dual-band frequencies. an antenna can also be useful for humans by implanting in them which is used for wearable applications [15][16] among antennae, the reconfigurable antennas have the capacity for selecting their parameters such as radiation, frequency, and polarization to redistribute the current to achieve the targeted frequency shifting. Reconfigurable antennas can overcome the challenges faced in designing portable devices. it can provide a good response in frequency, tunability, polarization, etc in a limited area. A tunable dipole antenna can also be inserted with PIN diodes. The tunability can be achieved by inserting different types of PIN diodes of resonant frequency [17]. When the reconfigurable antenna is designed by keePINg a rectangular resonator and PIN diode, it can be tuned from ultrawide band mode to narrowband mode [18][19].

Reconfigurable antennas have gained great attention in wireless communication devices and systems due to their ability of switching [20]. The reconfigurable antenna is mainly used compared to the multiband antenna due to its miniature size, higher gain, same type radiation pattern, etc [21]. Reconfigurable antenna with slot rings is designed using two PIN diodes gives high gain, return losses, good radiation pattern used in applications of WiMax/WiFi [22]. The 
reconfigurable antenna is simulated and fabricated. The comparison of pixel antenna results is shown and analyzed which gives a good frequency response [23][24]. the single PIN diode designed works in two different modes at a separate frequency to create a good pattern. They are used in the applications such as Cognitive Radio System, Satellite Application, Biomedical Application, filters, etc [25][26]. Among reconfigurable antennas, beam antenna has gained attention for data rate for the next generation of wireless communication technology used for 5G service, automotive radars[27]. The different slots in the antenna are designed for frequency and radiation using implemented PIN diodes. The radiation pattern is controllable by switching ON/OFF slots. Reconfigurable antennas are compact it can be fabricated easily [28][29].

\section{Design and Modelling:}

Figure 1 illustrates the 3-dimensional view of the presented design. The design consists of a superstrate of substrate layers made up of FR-4 based low-profile material. The FR-4 material has a 4.4 dielectric constant. The ground layer, patch, parasitic patch-1, and parasitic patch-2 are made up of copper material. The single PIN diode is connecting the two sections of the parasitic

patch-2. Due to the switching mechanism of PIN diodes ON and OFF the current distribution in the patch area is change and reconfigurability can be possible. Figure 2 illustrates the fabricated view of the presented design structure. The upper view of parasitic patch-2 without the PIN diode illustrate in Figure 2 (a). The upper view of parasitic patch-1 is illustrating in Figure 2 (b). The upper view of the parasitic patch illustrates in Figure 2(c). Figure 2 (d) illustrates the upper view of parasitic patch-2 with the PIN diode. Figure 2(e) represents the lateral view of the fabricated design structure.

The lateral view of the presented superstrate patch antenna is represented in figure 3(a). The patch, parasitic patch-1, parasitic patch -2, and ground layers are made up of copper material, and the thickness of these layers is $0.35 \mathrm{~mm}$. The size of these layers are respectively $28.4 \mathrm{~mm}$, $43.9 \mathrm{~mm}, 59 \mathrm{~mm}$, and $80.3 \mathrm{~mm}$. The substrate, substrate- 1 , and substrate- 2 are made up of dielectric material FR4, and the height of this unit is $1.6 \mathrm{~mm}$. The size of these all layers is the same as $80.3 \mathrm{~mm}$. The coaxial feed is used for the excitation of the presented design. The upper of the proposed structure without the substrate layers are illustrated in figure 3(b). The single PIN diode is positioned in the top location and connects two sections of the patch area. The patch, parasitic 
patch-1, and parasitic patch -2 are cropped from the corner. The dimensions of the trunked area are $4.8 \mathrm{~mm}$.

The dimensions of the superstrate antenna structure are calculated using the standard design equations (1-11) [30][31]. Equation (1) use for calculating resonance frequency calculation of the split ring resonators can be calculate using equation (1).

$$
f=\frac{1}{2 \pi \sqrt{L_{s}}}
$$

The Permittivity of a metamaterial antenna is represented by equation (2).

$$
\varepsilon_{\text {eff }}(f)=\varepsilon_{r}-\frac{\varepsilon_{r}-\varepsilon_{e s}}{1+G\left(\frac{f}{f_{d}}\right)^{2}}
$$

The Coefficients are mentioned below [32][33].

$$
\begin{gathered}
f_{d}=\frac{Z_{c}}{2 \mu_{0} h 1} \\
Z_{c}=\frac{1}{2 \pi} \sqrt{\frac{\mu_{0}}{\varepsilon_{\text {es }} \varepsilon_{0}}} * \log \left[F_{1} \frac{h}{w 1}+\sqrt{1+\left(\frac{2 h}{w 1}\right)^{2}}\right] \\
G=0.6+0.0009 Z_{c}
\end{gathered}
$$

The coefficients $\mathrm{F}_{1}$, relative electrostatic permittivity $\left(\varepsilon_{\mathrm{es}}\right)$, a1, b1 are as follows.

$$
\begin{gathered}
\mathrm{F}_{1}=6+(2 \pi-6) \exp \left[-\left(30.666 \frac{\mathrm{t}}{\mathrm{w} 1}\right)^{0.7528}\right. \\
\varepsilon_{\mathrm{es}}=\frac{\varepsilon_{\mathrm{r}}+1}{2}+\left(\frac{\varepsilon_{\mathrm{r}}-1}{2}\right)\left[1+10\left(\frac{\mathrm{t}}{\mathrm{w} 1}\right)\right]^{-\mathrm{a} 1 \mathrm{~b} 1} \\
\mathrm{a} 1=1+\frac{1}{49} \log \left[\frac{\left.\left(\frac{\mathrm{W}}{\mathrm{t}}\right)^{4}+\left(\frac{\mathrm{w}}{52 \mathrm{t}}\right)^{2}\right]+\frac{1}{\left(\frac{\mathrm{w}}{\mathrm{t}}\right)^{4}+0.432}\left[1+\left(\frac{1}{18.1} \frac{\mathrm{w}}{\mathrm{t}}\right)^{3}\right]}{\mathrm{b} 1=0.564\left(\frac{\varepsilon_{\mathrm{r}}-0.9}{\varepsilon_{\mathrm{r}}+3.0}\right)^{0.053}}\right.
\end{gathered}
$$

The scattering parameters are used to analyze the antenna's output at high frequencies. As seen in the equation, the transmittance $\left(S_{21}\right)$, and reflectance $\left(S_{11}\right)$ are needed to determine refractive index and impedance. [34]. 


$$
\begin{gathered}
\mathrm{z}=\sqrt{\frac{\left(1+\mathrm{S}_{11}^{2}\right)-\mathrm{S}_{21}^{2}}{\left(1-\mathrm{S}_{11}^{2}\right)-\mathrm{S}_{21}^{2}}} \\
\mathrm{n}=\frac{1}{\mathrm{kd}} \cos ^{-1}\left[\frac{1}{2 \mathrm{~S}_{21}}\left(1-\mathrm{S}_{11}^{2}+\mathrm{S}_{21}^{2}\right)\right]
\end{gathered}
$$

Where $\mathrm{d}$ represents the layer thickness, $\mathrm{n}$ represents the refractive ratio, and $\mathrm{k}$ represents the wave vector. The wave impedance of the substrate is denoted by $\mathrm{z}$.

The presented architecture reflects frequency reconfigurability by switching the direction of the switch ON/OFF. For the RF switch, a PIN diode is required. Figure 4 depicts the electric alternative circuit of a PIN diode and the HFSS tool simulator model. The proposed structure has been modeled for $50 \mathrm{ohms}$. In figure 4 (a), The HFSS model represents two sections of a patch that are linked by RLC components that are lumped together in figure 4 (b), the switch-ON state is expressed by the inductor (Ls), and resistor (Rs) are joint in series are shown in figure 4(c), the switch-OFF condition is described by a resistor $(\mathrm{Rp})$ and a capacitor $(\mathrm{Cp})$ are joint in series with an inductor (Ls). Figure 5 depicts the simulated and fabricated effects for the turn $\mathrm{ON}$ and switch OFF configurations. A good amount of similarity among both the results is observed.

Figure 6(a) represents the reflectance response curve for the $1 \mathrm{GHz}$ to $3 \mathrm{GHz}$ frequency range. Two modes are considered based upon the switching acting action of PIN diodes (ON and OFF). Figure 6(b) representants the first frequency tunable bands for the range of $1.4 \mathrm{GHz}$ to 1.8 $\mathrm{GHz}$. The resonating frequency is located at $1.55 \mathrm{GHz}$ with the reflectance response of $-11.09 \mathrm{~dB}$ during the PIN diode $\mathrm{ON}$ condition. The resonating frequency is located at $1.65 \mathrm{GHz}$ with a reflectance response of $-22.56 \mathrm{~dB}$ during the PIN diode OFF condition. Figure 6(c) representants the first frequency tunable bands during $2.3 \mathrm{GHz}$ to $2.7 \mathrm{GHz}$. The resonating frequency is located at $2.55 \mathrm{GHz}$ with a reflectance response of $-18.81 \mathrm{~dB}$ during the PIN diode ON condition. The resonating frequency is located at $2.49 \mathrm{GHz}$ with a reflectance response of $-13.43 \mathrm{~dB}$ during the PIN diode OFF condition.

Figure 7 illustrates the contour plot (fermi plot)of the variation of feed position versus reflectance response for the switch $\mathrm{ON}$ configuration. Figure 7(a) illustrates the variation of feed position in the $\mathrm{X}$ side $(28 \mathrm{~mm}$ to $47 \mathrm{~mm}$ ) to observe the reflectance response for the range of 1 $\mathrm{GHz}$ to $3 \mathrm{GHz}$. There are three bands of reflectance response $\left(\mathrm{S}_{11}\right)$ are observed at $1.2,1.55$, and $2.55 \mathrm{GHz}$. Figure 7(b) illustrates the variation of feed position in the Y side (28 $\mathrm{mm}$ to $47 \mathrm{~mm})$ to observe the reflectance response for the range of $1 \mathrm{GHz}$ to $3 \mathrm{GHz}$. There are three bands of 
reflectance response $\left(S_{11}\right)$ are observed at 1.2, 1.5, 1.55, 2.5, and 2.8 GHz. Therefore, more bands are observed for the feed position variation in Y-side.

Figure 8 illustrates the contour plot (fermi plot) of the variation of feed position versus reflectance response for the switch OFF configuration. Figure 8(a) illustrates the variation of feed position in the $\mathrm{X}$ side $(28 \mathrm{~mm}$ to $47 \mathrm{~mm}$ ) to observe the reflectance response for the range of 1 $\mathrm{GHz}$ to $3 \mathrm{GHz}$. There are three bands of reflectance response $\left(\mathrm{S}_{11}\right)$ are observed at $1.2 \mathrm{GHz}, 1.53$ $\mathrm{GHz}, 1.62 \mathrm{GHz}$, and $2.5 \mathrm{GHz}$. Figure 8(b) illustrates the variation of feed position in the Y side ( $28 \mathrm{~mm}$ to $47 \mathrm{~mm}$ ) to observe the reflectance response for the range of $1 \mathrm{GHz}$ to $3 \mathrm{GHz}$. There are three bands of reflectance response $\left(S_{11}\right)$ are observed at $1.2,1.5,1.62,2.5$, and $2.85 \mathrm{GHz}$. Therefore, more bands are observed for the feed position variation in Y-side. Figure 8 illustrates the contour plot of the slot of patch position variation versus reflectance response for the switch ON configuration. The slot position is varying on the Y side from $28 \mathrm{~mm}$ to $34 \mathrm{~mm}$. Three bands of reflectance response are observed at $1.25,1.55$, and $2.5 \mathrm{GHz}$.

Directivity represents the radiation effects of the antenna. Figure 10(a) illustrates the directivity plot of the Switch ON and OFF modes for the $-180^{\circ}$ to $+180^{\circ}$. The value of directivity in switch ON mode and OFF modes are respectively $6.98 \mathrm{~dB}$ and $6.60 \mathrm{~dB}$. The broadband directivity is observed in switch $\mathrm{ON}$ and OFF modes. Figure 10(b) illustrates the normalized directivity plot for the Switch ON mode is $83^{0}\left(-48^{0}\right.$ to $\left.+35^{0}\right)$, and $88^{0}\left(-48^{0}\right.$ to $\left.+40^{0}\right)$. The efficiency of an antenna can be identified based upon the gain of an antenna. Figure 11 (a) represents the total gain of switch OFF mode is $3.447 \mathrm{~dB}$. Figure 11 (b) represents the total gain of switch ON mode is $3.683 \mathrm{~dB}$.

Table 1 represents the different values of S11, bandwidth, and gain for the given band with switch ON and switch OFF conditions. It is observed the maximum reflectance response of -22.56 $\mathrm{dB}$ is observed at $1.65 \mathrm{GHz}$. The $70 \mathrm{MHz}$ of maximum bandwidth is attained, and a gain of 3.683 $\mathrm{dB}$ possible in the switch $\mathrm{ON}$ modes. Table -2 represents there are two tunable frequency bands due to the switch ON and switch OFF. The first band represents the tunability of $100 \mathrm{MHz}$ and the second band provides the tunability of $60 \mathrm{MHz}$.

\section{Conclusion :}

The presented manuscript is a solution for achieving frequency tunability. The tunability is achieved using the single PIN diode. The top located PIN diode helps to reduce the complexity 
to make it $\mathrm{ON}$ and OFF. Corner truncation makes the better reflectance response is achieved with the better gain. Variation of feed position and slot position is carried out to identify the best response. The structure provides the maximum tunability of $100 \mathrm{MHz}$. The minimum reflectance coefficient $\left(\mathrm{S}_{11}\right)$ of $-22.56 \mathrm{~dB}$ is achieved at $1.65 \mathrm{~dB}$. The healthy gain is achieved in both the switching modes. The $3.683 \mathrm{~dB}$ maximum gain is attained. The broader directivity of $88^{0}$ is achieved. Due to the novel design approach multiband tunability, good gain, and directivity are achieved with the low-profile substrate (FR-4). This design suitable for Wifi, GPS, and many more wireless communication applications.

\section{Figure-1:}

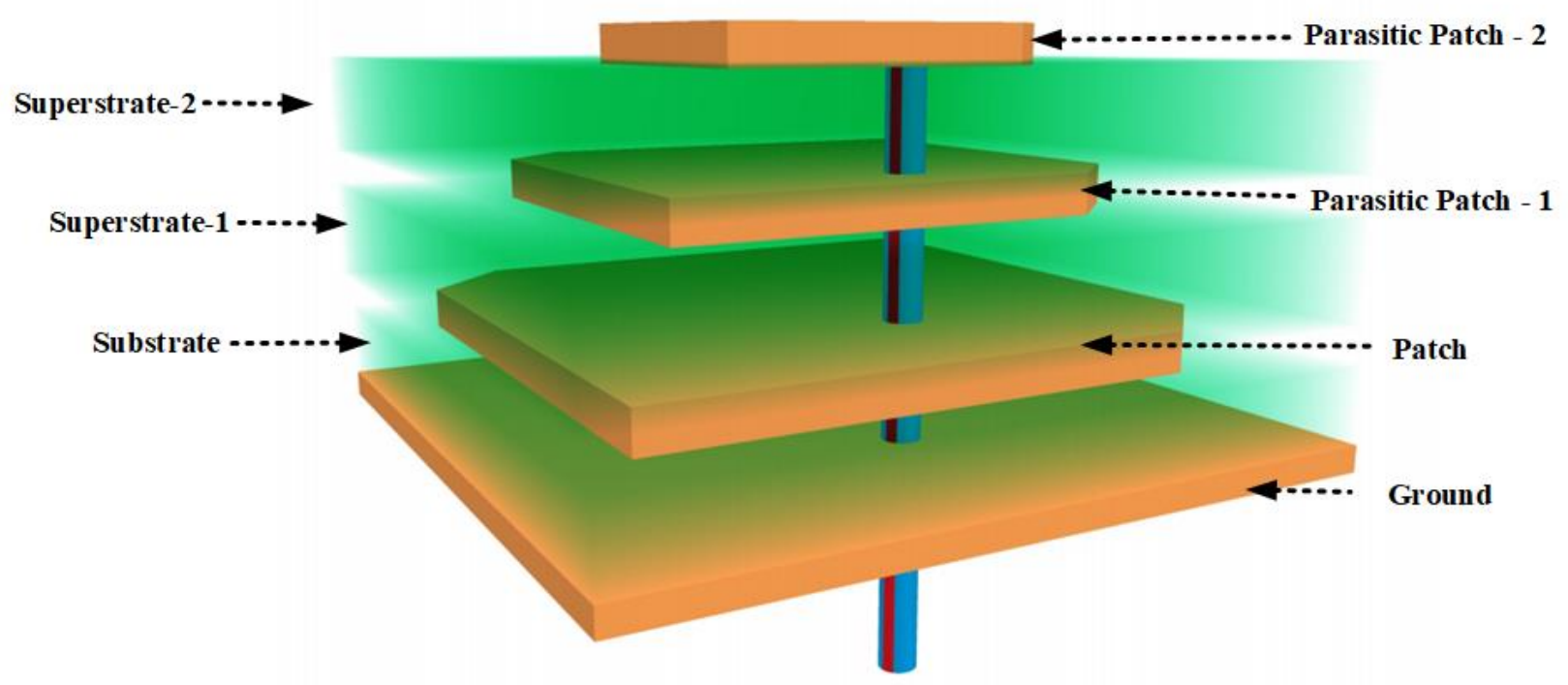

A three-dimensional representation of the proposed superstrate patch antenna system. 


\section{Figure-2:}

(a)

(b)

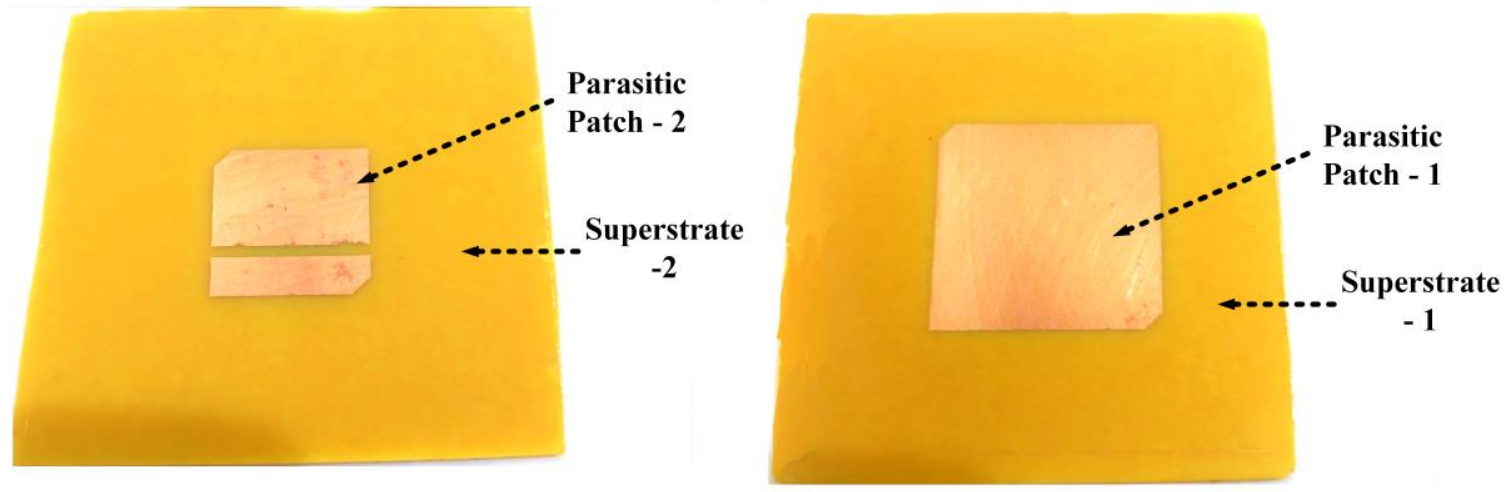

(c)

(d)

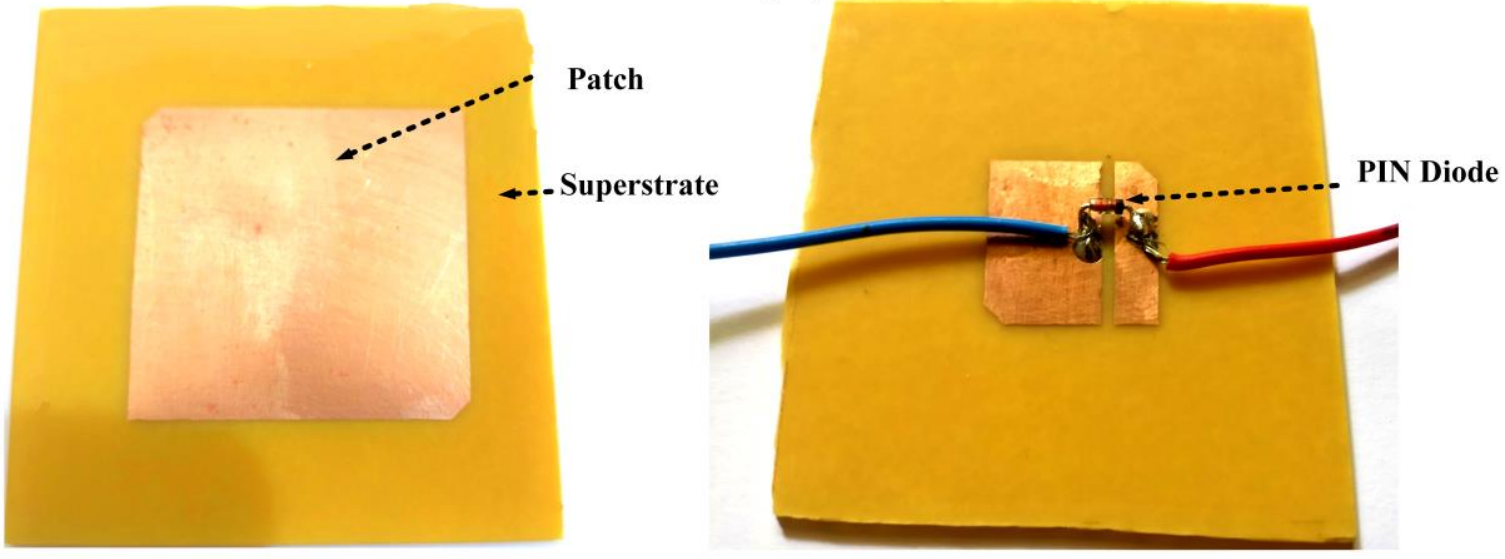

(e)

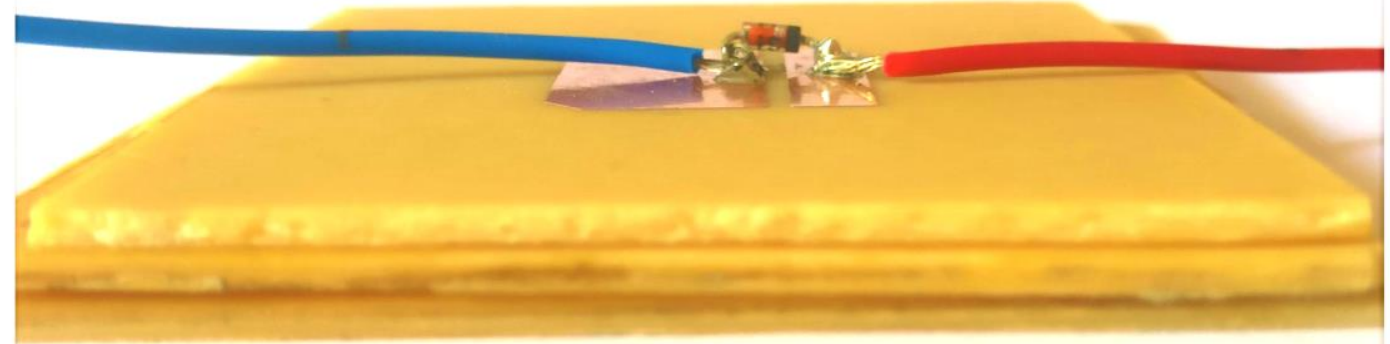

Prototype of the fabricated antenna structure. (a) The upper view of parasitic patch-2 without the PIN diode. (b) The upper view of parasitic patch-1. (c) The upper view of the parasitic patch. (d) The upper view of parasitic patch-2 with the PIN diode. (e) The lateral view of fabricated design structure. 
Figure-3:

(a)

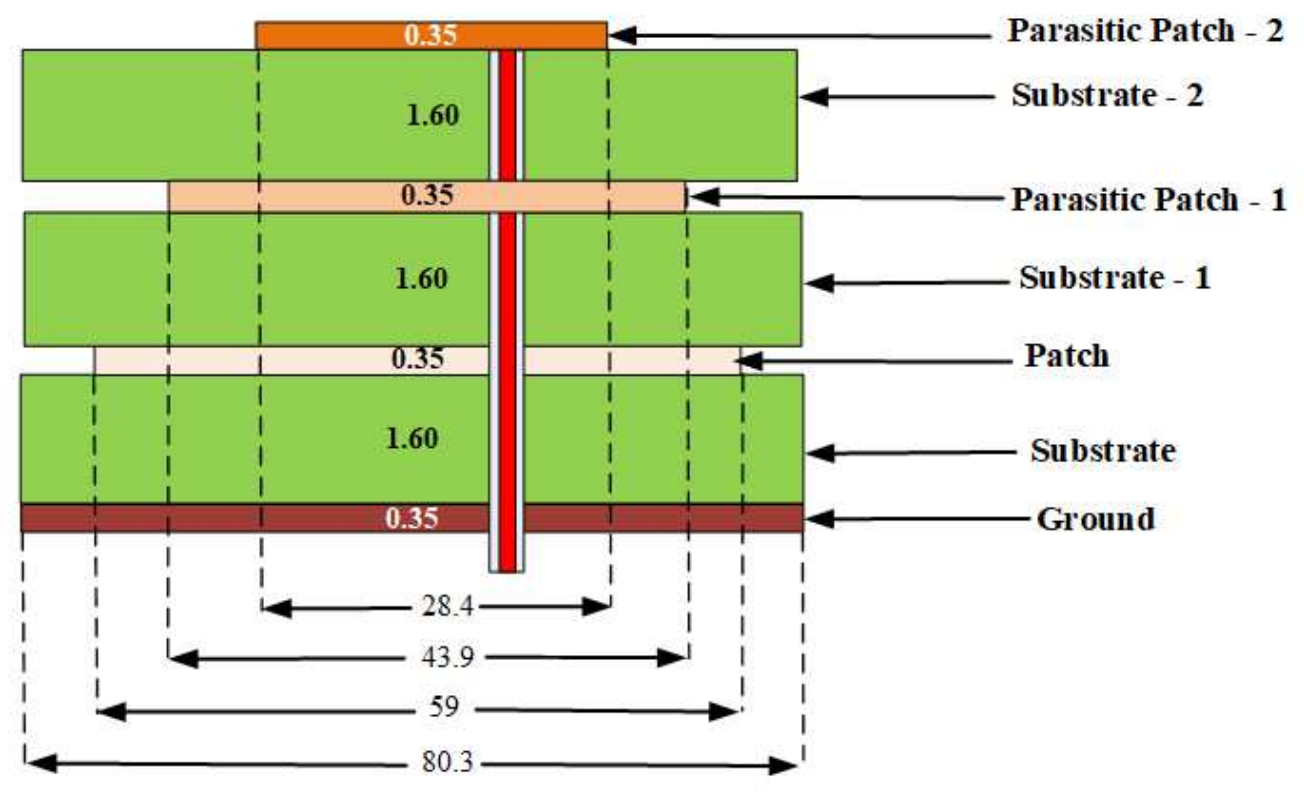

(b)

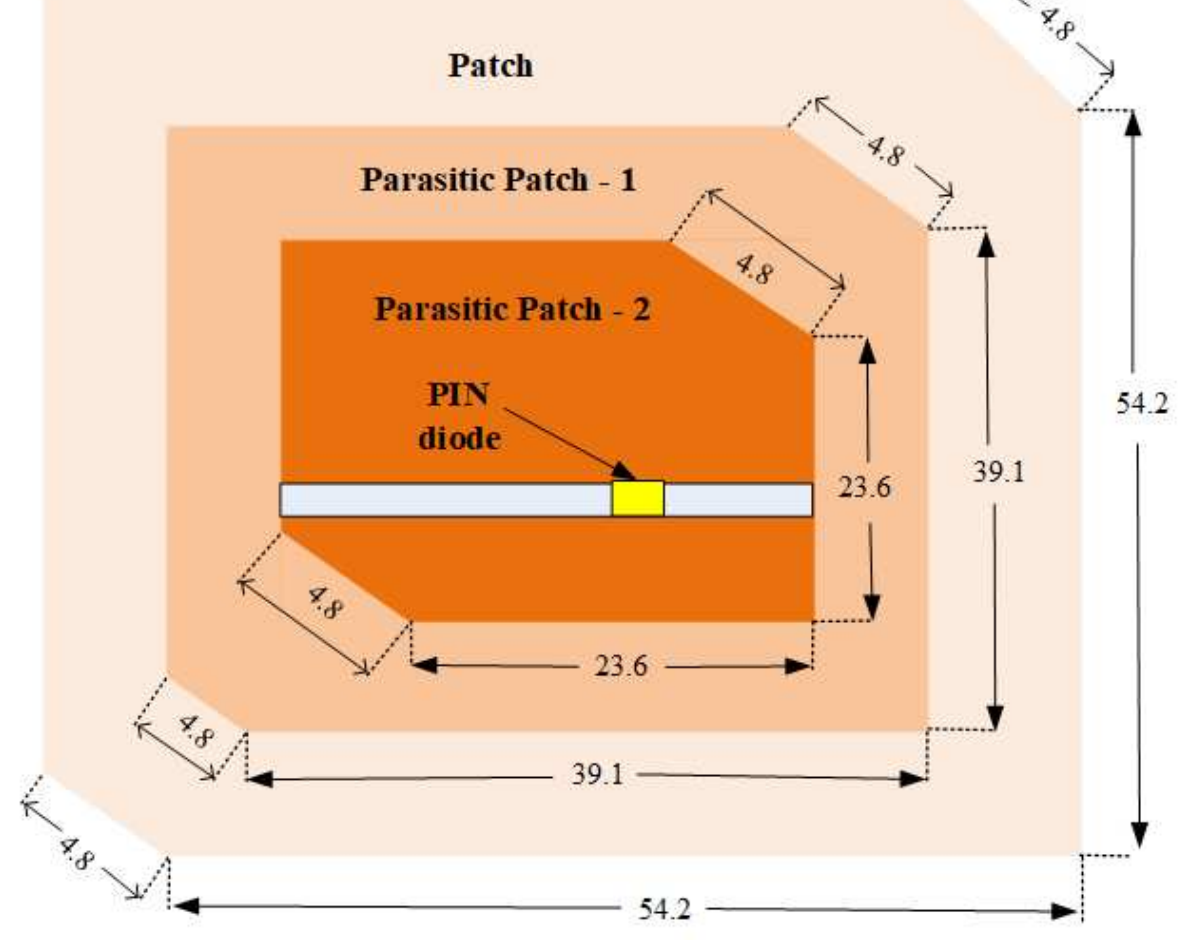

(a) Sideview of the proposed superstrate patch antenna. (b) Topview of proposed superstrate structure without the substrate material. 
Figure-4:

(a)

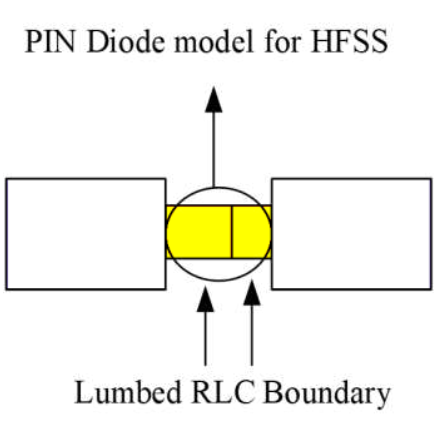

(b)

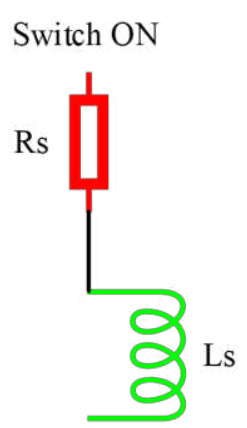

(c)

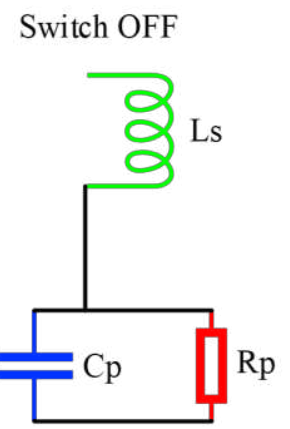

PIN Diode Model (a) The Lumbed R-L-C Boundary generated for the tool HFSS (b) Depiction of PIN Diode ON state (c) Representation of PIN Diode OFF state 
Figure-5:

(a)
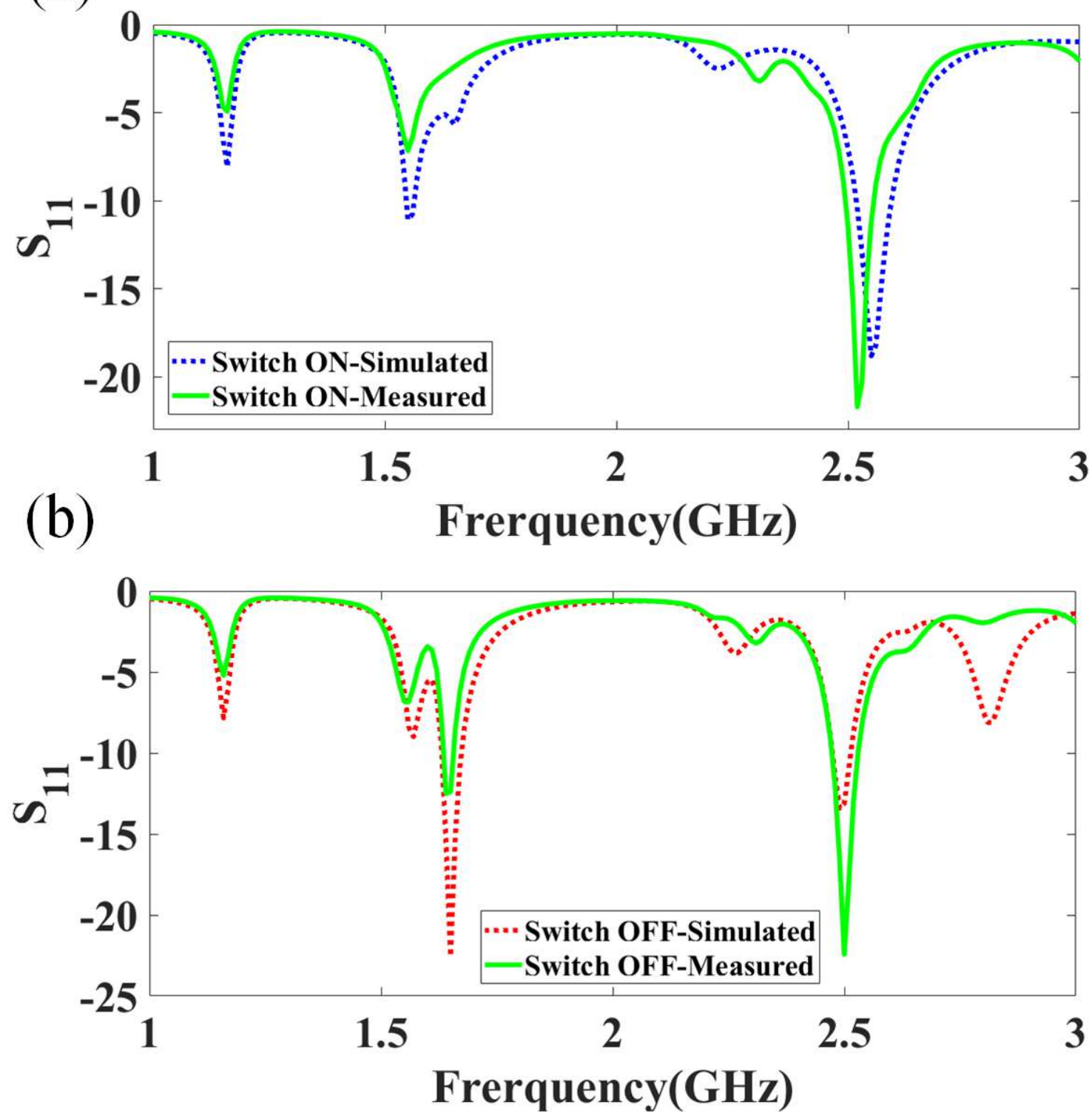

Simulated and fabricated reflectance response $\left(\mathrm{S}_{11}\right)$ results using three PIN diodes switch-ON and switch-OFF are presented for the 1 to $3 \mathrm{GHz}$ frequency range. 
Figure-6:

(a)

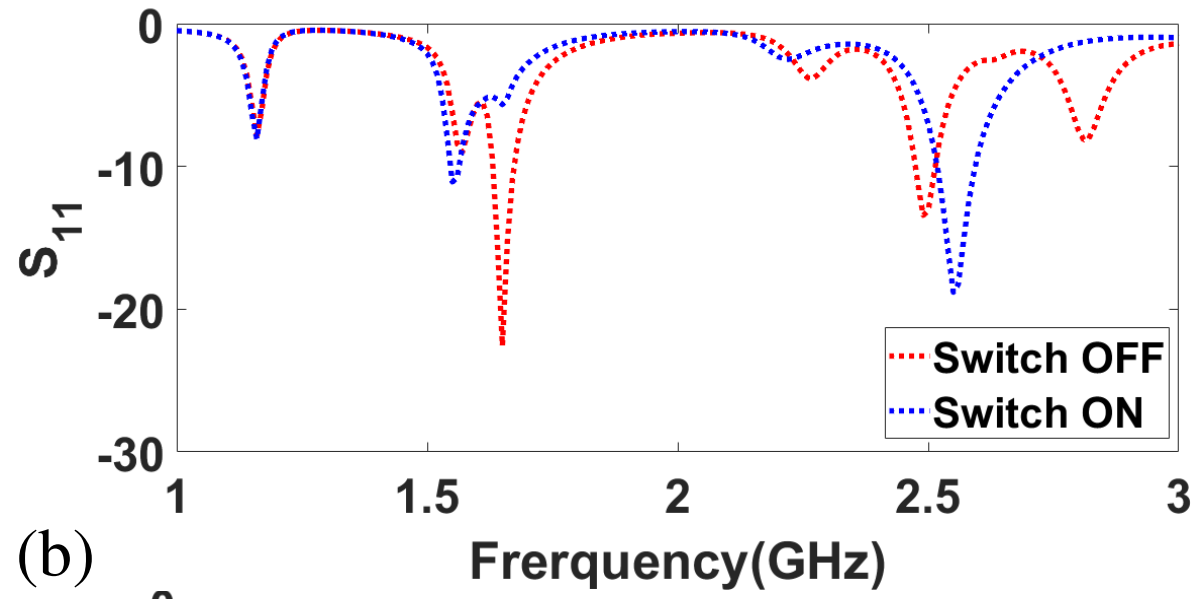

(b)

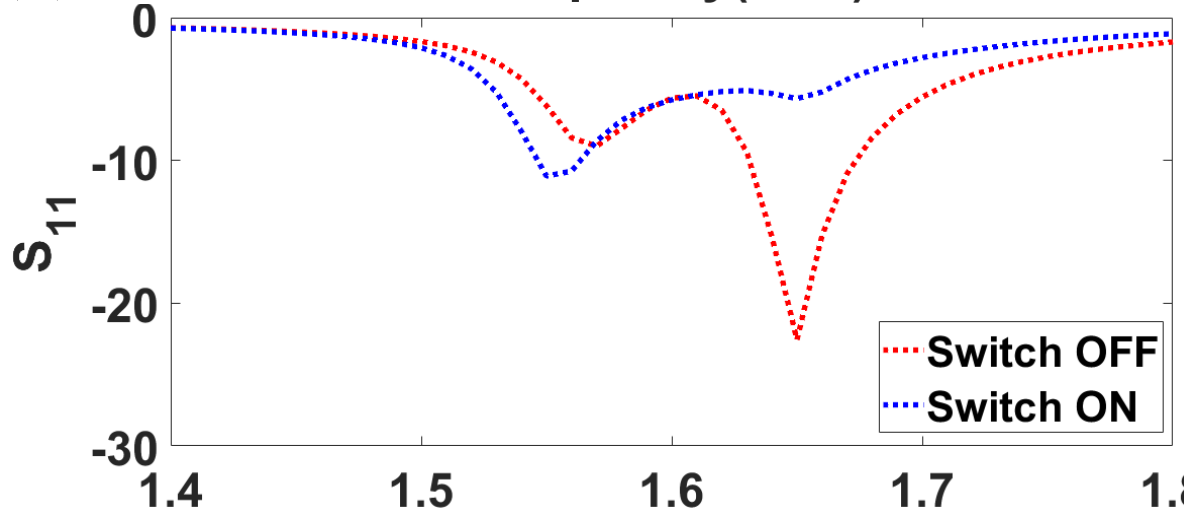

(c)

1.6

1.8
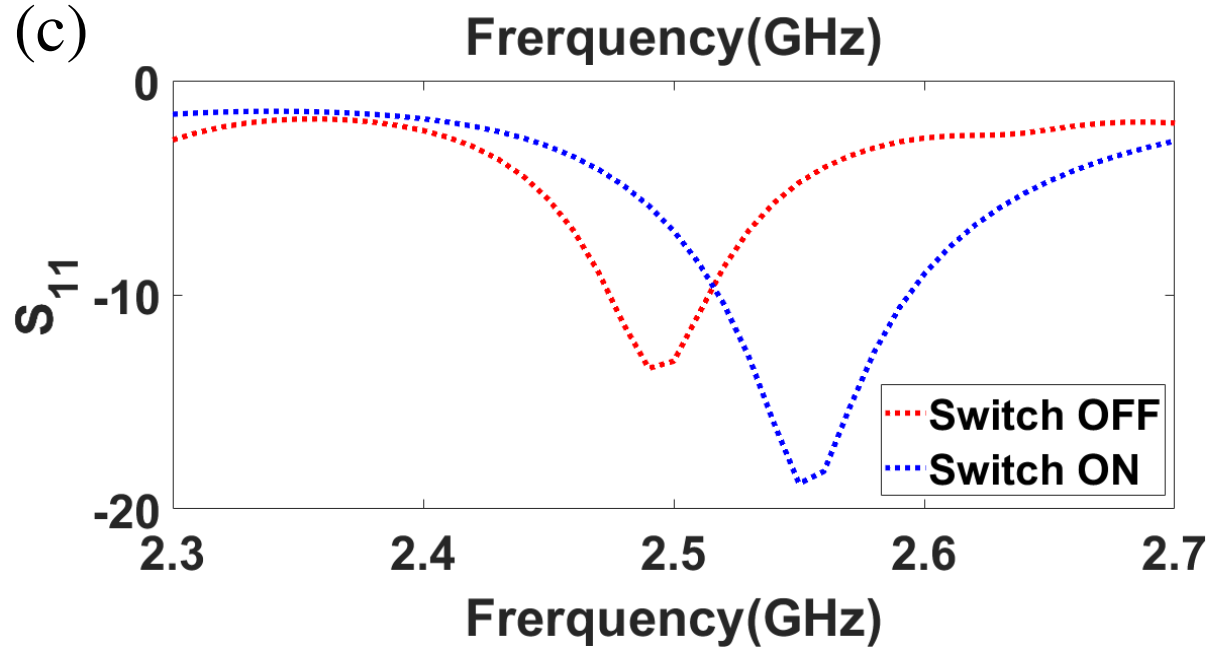

(a) $\mathrm{S}_{11}$ plot for two switching conditions of the PIN diode for the frequency band of $1 \mathrm{GHz}$ to 3

GHz. (b) The first frequency tunable band shifts $1.55 \mathrm{GHz}$ to $1.65 \mathrm{GHz}$ and return loss is improved from $-11.09 \mathrm{~dB}$ to $-22.56 \mathrm{~dB}$. (c) The second frequency tunable band shifts $2.55 \mathrm{GHz}$ to $2.49 \mathrm{GHz}$ and return loss is improved from $-18.81 \mathrm{~dB}$ to $-13.43 \mathrm{~dB}$. 
Figure-7:

(a)
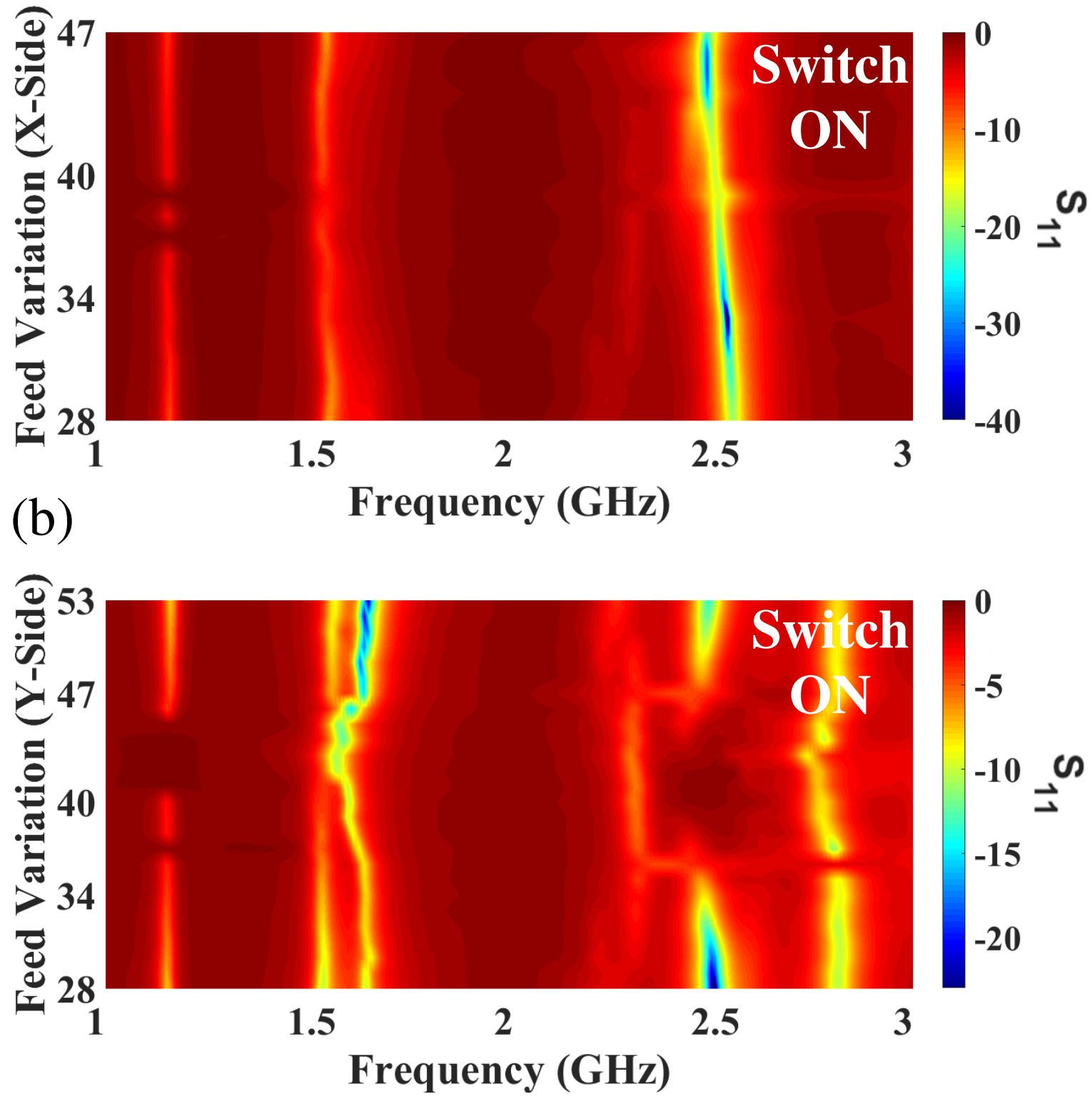

Contour plot of the variation of feed position versus reflectance response for the switch ON configuration. (a) Variation of feed position in the $X$ side for $28 \mathrm{~mm}$ to $47 \mathrm{~mm}$. (b) Variation of feed position in the $\mathrm{Y}$ side for $28 \mathrm{~mm}$ to $53 \mathrm{~mm}$. 
Figure-8:

(a)
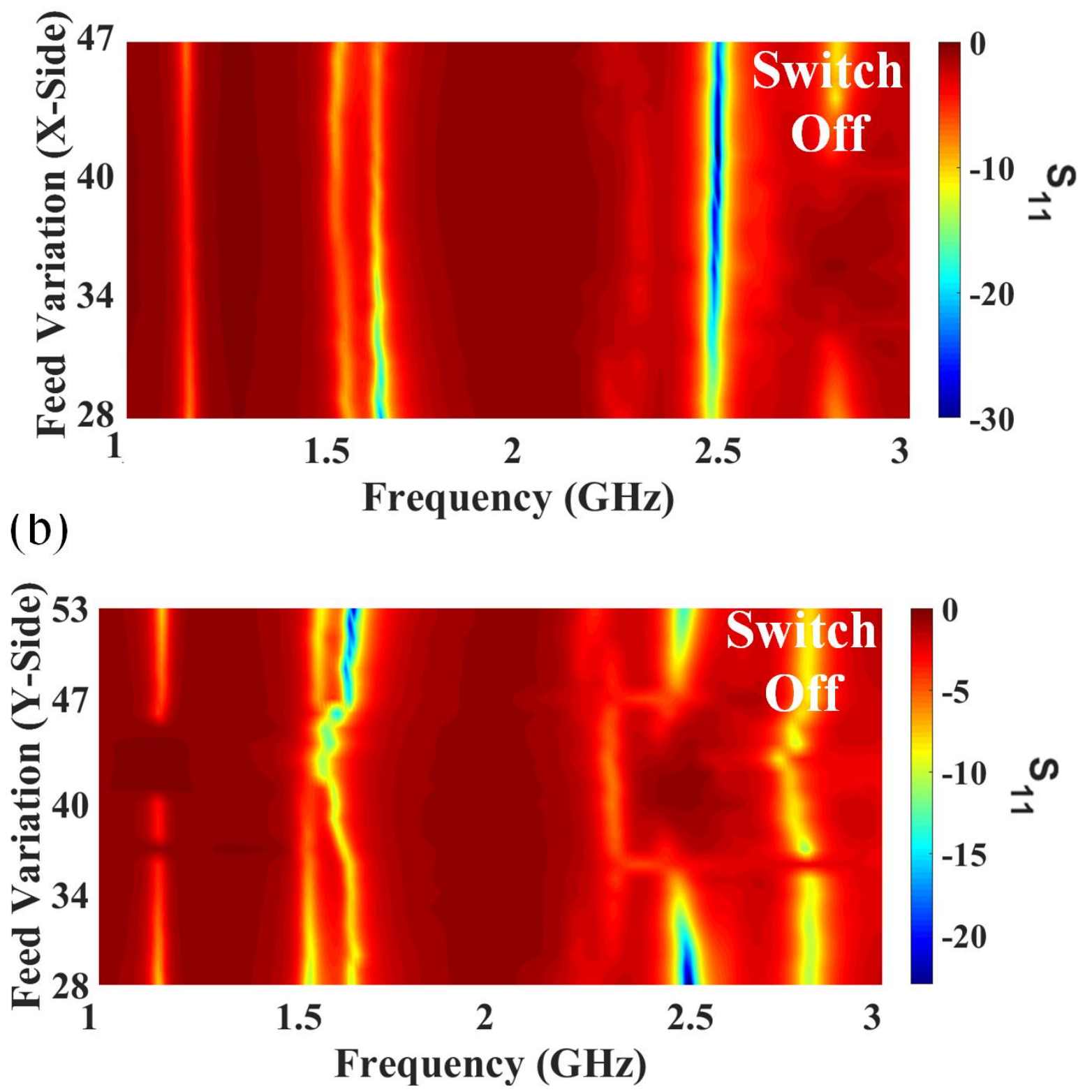

Contour plot of the variation of feed position versus reflectance response for the switch OFF configuration. (a) Variation of feed position in the $\mathrm{X}$ side for $28 \mathrm{~mm}$ to $47 \mathrm{~mm}$. (b) Variation of feed position in the $\mathrm{Y}$ side for $28 \mathrm{~mm}$ to $53 \mathrm{~mm}$. 
Figure-9:

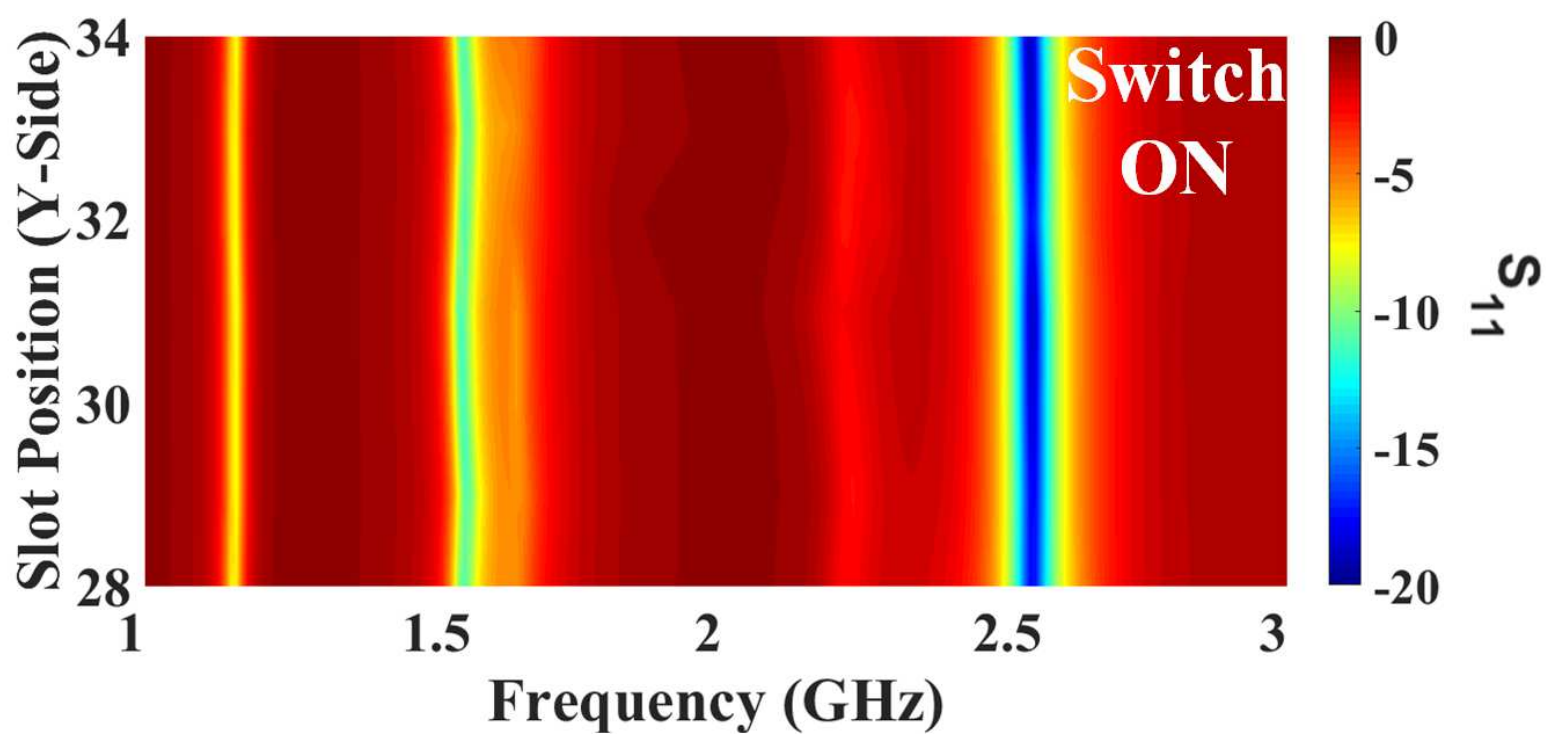

Contour plot of the slot of patch position variation versus reflectance response for the switch ON configuration. The slot position is varying on the $\mathrm{Y}$ side from $28 \mathrm{~mm}$ to $34 \mathrm{~mm}$. 
Figure-10:

(a)
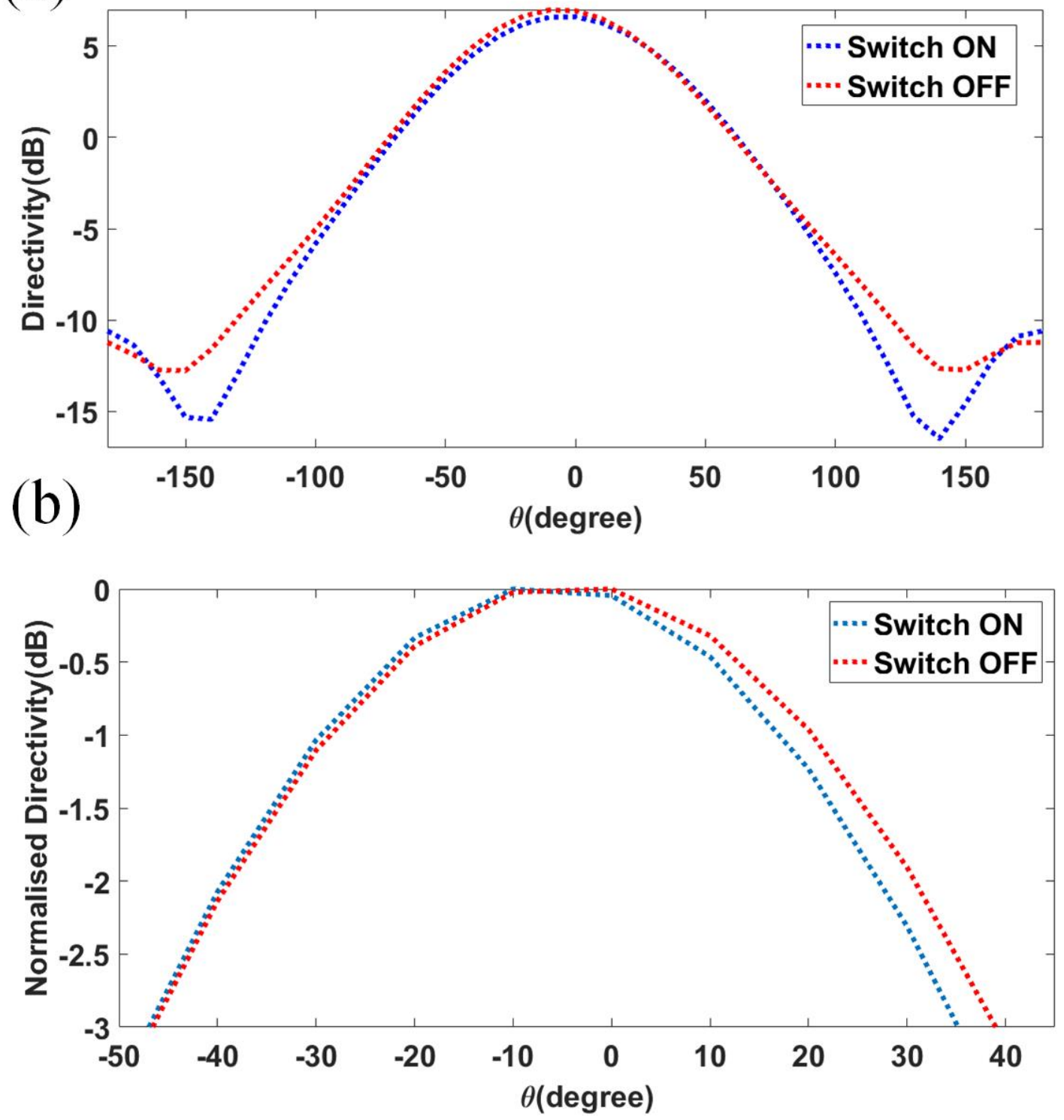

(a) Directivity plot of the Switch ON and OFF modes for the $-180^{\circ}$ to $+180^{\circ}$. The value of directivity in switch ON mode and OFF modes are respectively $6.98 \mathrm{~dB}$ and $6.60 \mathrm{~dB}$. (b) The normalized directivity plot for the Switch ON mode is $83^{0}\left(-48^{0}\right.$ to $\left.+35^{0}\right)$, and $88^{0}\left(-48^{0}\right.$ to $\left.+40^{0}\right)$. 
Figure-11:

\section{(a)}
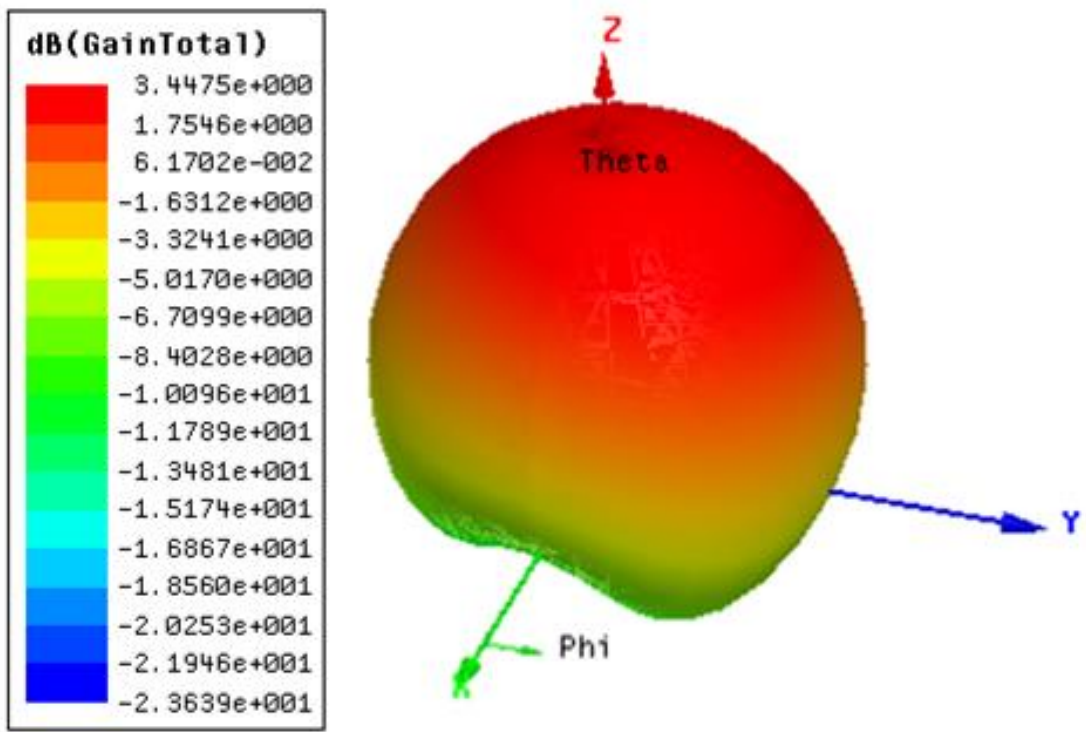

(b)
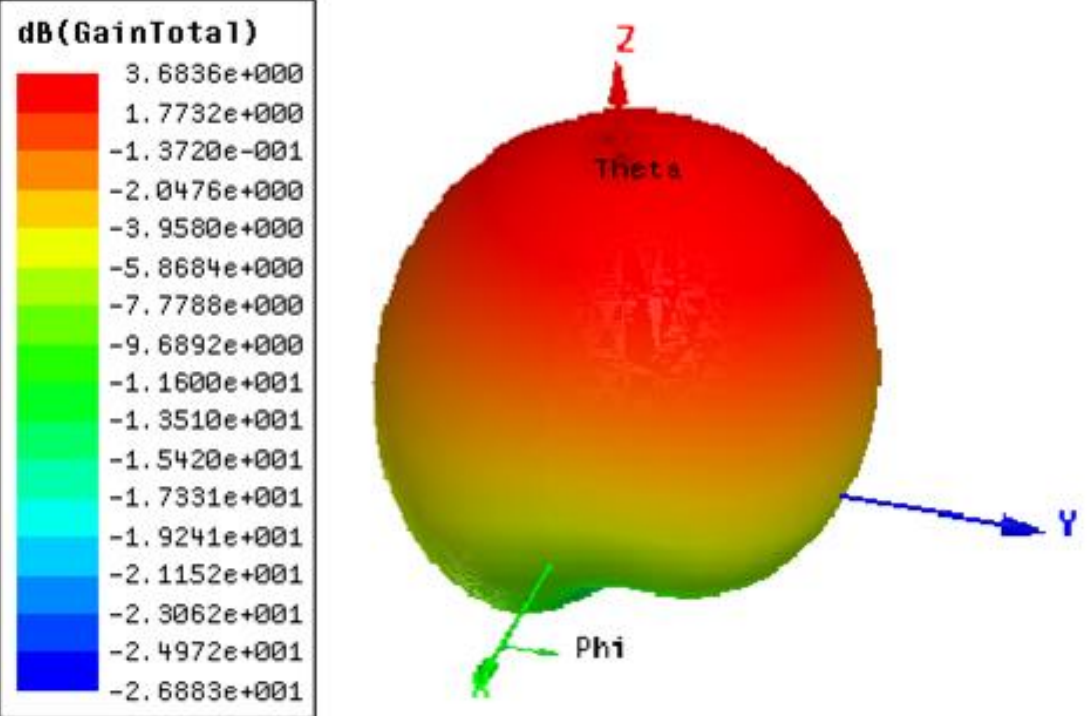

(a) Total gain for the switch OFF mode is $3.447 \mathrm{~dB}$. (b) The total gain for the switch ON mode is $3.683 \mathrm{~dB}$. 
Table-1 : Tabular representation of switching modes, reflection coefficient, resonance frequency, bandwidth, and total gain.

\begin{tabular}{|l|l|l|l|l|}
\hline Switching Modes & $\begin{array}{l}\text { Reflection } \\
\text { coefficient }\left(\mathrm{S}_{11}\right)\end{array}$ & $\begin{array}{l}\text { Resonance } \\
\text { frequency }\end{array}$ & Bandwidth & Total Gain \\
\hline Switch ON & $-11.09 \mathrm{~dB}$ & $1.55 \mathrm{GHz}$ & $10 \mathrm{MHz}$ & $3.683 \mathrm{~dB}$ \\
& $-18.81 \mathrm{~dB}$ & 2.55 & $70 \mathrm{MHz}$ & \\
\hline Switch OFF & $-22.56 \mathrm{~dB}$ & $1.65 \mathrm{GHz}$ & $30 \mathrm{MHz}$ & $3.447 \mathrm{~dB}$ \\
& $-13.43 \mathrm{~dB}$ & $2.49 \mathrm{GHz}$ & $40 \mathrm{MHz}$ & \\
\hline
\end{tabular}


Table-2: Frequency tunability analysis due to switching ON and OFF modes.

\begin{tabular}{|c|c|c|}
\hline Sr.no. & Tunable band -1 & Tunable band -2 \\
\hline 1 & $100 \mathrm{MHz}(1.65 \mathrm{GHz}-1.55 \mathrm{GHz})$ & $60 \mathrm{MHz}(2.55 \mathrm{GHz}-2.49 \mathrm{GHz})$ \\
\hline
\end{tabular}


Table-3: The proposed design is compared to previously reported work.

\begin{tabular}{|c|c|c|c|c|}
\hline References & Size $\left(\mathrm{mm}^{2}\right)$ & $\begin{array}{c}\text { Actuators (PIN } \\
\text { diode) }\end{array}$ & Bandwidth (MHz) & Gain (dB) \\
\hline Presented work & $80.3 \times 80.3$ & 1 & 70 & 3.683 \\
\hline$[35]$ & $80 \times 45.8$ & 5 & $180 / 200 / 180 / 200$ & 3 \\
\hline$[36]$ & $50 \times 50$ & 4 & - & 5.08 \\
\hline$[37]$ & $70 \times 70$ & 4 & $400 / 500$ & - \\
\hline$[38]$ & $40 \times 30$ & 4 & 8800 & 4.1 \\
\hline$[39]$ & $75 \times 75$ & 4 & 4300 & 6.8 \\
\hline$[40]$ & $80 \times 60$ & 6 & & \\
\hline
\end{tabular}




\section{References:}

[1] M. Allayioti, J. R. Kelly, and R. Mittra, "Beam and polarization reconfigurable microstrip antenna based on parasitics," Microw. Opt. Technol. Lett., 2018, doi: 10.1002/mop.31184.

[2] M. Jusoh, T. Aboufoul, T. Sabapathy, A. Alomainy, and M. R. Kamarudin, "Patternreconfigurable microstrip patch antenna with multidirectional beam for WiMAX application," IEEE Antennas Wirel. Propag. Lett., 2014, doi:

10.1109/LAWP.2014.2320818.

[3] Y. Cao et al., "Broadband and High-Gain Microstrip Patch Antenna Loaded With Parasitic Mushroom-Type Structure,” IEEE Antennas Wirel. Propag. Lett., 2019, doi: 10.1109/LAWP.2019.2917909.

[4] H. A. Bakar, R. A. Rahim, P. J. Soh, and P. Akkaraekthalin, "Liquid-based reconfigurable antenna technology: Recent developments, challenges and future," Sensors (Switzerland). 2021, doi: 10.3390/s21030827.

[5] S. K. Patel, K. H. Shah, and J. S. Sonagara, "Broadband liquid metamaterial radome design," Waves in Random and Complex Media, 2020, doi: 10.1080/17455030.2018.1506597.

[6] D. T. Phan-Huy et al., "Single-Carrier Spatial Modulation for the Internet of Things: Design and Performance Evaluation by Using Real Compact and Reconfigurable Antennas," IEEE Access, 2019, doi: 10.1109/ACCESS.2019.2895754.

[7] S. K. Patel, C. Argyropoulos, and Y. P. Kosta, "Broadband compact microstrip patch antenna design loaded by multiple split ring resonator superstrate and substrate," Waves in Random and Complex Media, vol. 27, no. 1, pp. 92-102, Jan. 2017, doi:

10.1080/17455030.2016.1203081.

[8] M. M. Hasan, M. R. I. Faruque, and M. T. Islam, "Dual band metamaterial antenna for LTE/bluetooth/WiMAX system,” Sci. Rep., 2018, doi: 10.1038/s41598-018-19705-3.

[9] P. Liu, W. Jiang, S. Sun, Y. Xi, and S. Gong, "Broadband and Low-Profile PentaPolarization Reconfigurable Metamaterial Antenna," IEEE Access, 2020, doi: 10.1109/ACCESS.2020.2969488.

[10] N. O. Parchin, H. J. Basherlou, Y. I. A. Al-Yasir, A. M. Abdulkhaleq, and R. A. AbdAlhameed, "Reconfigurable antennas: Switching techniques - a survey," Electronics (Switzerland). 2020, doi: 10.3390/electronics9020336. 
[11] S. K. Patel, C. Argyropoulos, and Y. P. Kosta, "Pattern controlled and frequency tunable microstrip antenna loaded with multiple split ring resonators," IET Microwaves, Antennas Propag., 2018, doi: 10.1049/iet-map.2017.0319.

[12] S. JAYDEEP and L. SUNIL, "an Investigation on Recent Trends in Metamaterial Types and Its Applications," i-manager's J. Mater. Sci., vol. 5, no. 4, p. 55, 2018, doi: 10.26634/jms.5.4.13974.

[13] Y. Dong and T. Itoh, "Metamaterial-based antennas," 2012, doi: 10.1109/JPROC.2012.2187631.

[14] J. Wang et al., "Metantenna: When Metasurface Meets Antenna Again," IEEE Trans. Antennas Propag., 2020, doi: 10.1109/TAP.2020.2969246.

[15] D. A. Sehrai, F. Muhammad, S. H. Kiani, Z. H. Abbas, M. Tufail, and S. Kim, "Gainenhanced metamaterial based antenna for $5 \mathrm{G}$ communication standards," Comput. Mater. Contin., 2020, doi: 10.32604/cmc.2020.011057.

[16] S. Roy and U. Chakraborty, "Metamaterial Based Dual Wideband Wearable Antenna for Wireless Applications," Wirel. Pers. Commun., 2019, doi: 10.1007/s11277-019-06206-3.

[17] J. Choi and S. Lim, "Frequency reconfigurable metamaterial resonant antenna," 2009, doi: 10.1109/APMC.2009.5384271.

[18] A. Vamseekrishna, B. T. P. Madhav, Y. Nagarjuna, S. Lakshmi Manasa, V. Mourya, and Y. Yaswant, "Reconfigurable notch band antenna using pin diodes," J. Adv. Res. Dyn. Control Syst., 2017.

[19] J. Kumar, B. Basu, and F. A. Talukdar, "Modeling of a PIN diode RF switch for reconfigurable antenna application,”Sci. Iran., 2019, doi: 10.24200/sci.2018.20110.

[20] “A Novel Frequency Reconfigurable Microstrip Patch Antenna using Pin Diode,” Int. J. Innov. Technol. Explor. Eng., 2020, doi: 10.35940/ijitee.e3047.039520.

[21] J. H. Lim, G. T. Back, Y. Il Ko, C. W. Song, and T. Y. Yun, “A reconfigurable PIFA using a switchable PIN-diode and a fine-tuning varactor for USPCS/WCDMA/mWiMAX/WLAN," IEEE Trans. Antennas Propag., 2010, doi: 10.1109/TAP.2010.2048849.

[22] Y. I. A. Ai-Yasir, N. OjaroudiParchin, A. Alabdullah, W. Mshwat, A. Ullah, and R. AbdAlhameed, "New Pattern Reconfigurable Circular Disk Antenna Using Two PIN Diodes for WiMax/WiFi (IEEE 802. 11 a) Applications," 2019, doi: 
10.1109/SMACD.2019.8795287.

[23] E. Carrasco, M. Barba, and J. A. Encinar, "X-band reflectarray antenna with switchingbeam using PIN diodes and gathered elements," IEEE Trans. Antennas Propag., 2012, doi: 10.1109/TAP.2012.2208612.

[24] R. George, C. R. S. Kumar, S. Gangal, and M. Joshi, "Frequency reconfigurable pixel antenna with PIN diodes," Prog. Electromagn. Res. Lett., 2019, doi: 10.2528/pier119051803.

[25] P. VIDHI, J. D. RAMESH, and L. SUNIL, "NEW APPROACH OF HIGH POWER TESTING OF SPACECRAFT PASSIVE COMPONENTS USING DIPLEXER," $i$ manager's J. Commun. Eng. Syst., vol. 9, no. 1, p. 1, 2020, doi: 10.26634/jcs.9.1.17395.

[26] A. A. Palsokar and S. L. Lahudkar, "Frequency and pattern reconfigurable rectangular patch antenna using single PIN diode," AEU - Int. J. Electron. Commun., 2020, doi: 10.1016/j.aeue.2020.153370.

[27] J. Hur et al., "Reconfigurable Beamforming Silicon Plasma Antenna with Vertical PIN Diode Array," Adv. Electron. Mater., 2020, doi: 10.1002/aelm.202000257.

[28] S. Nikolaou et al., "Pattern and frequency reconfigurable annular slot antenna using pin diodes," IEEE Trans. Antennas Propag., 2006, doi: 10.1109/TAP.2005.863398.

[29] "Frequency Reconfigurable Antenna using PIN Diodes," Int. J. Eng. Adv. Technol., 2019, doi: 10.35940/ijeat.a1019.1291s52019.

[30] S. P. lavadiya, S. k. Patel, and R. Maria, "High Gain and Frequency Reconfigurable Copper and Liquid Metamaterial Tooth Based Microstrip Patch Antenna," AEU - Int. J. Electron. Commun., p. 153799, May 2021, doi: 10.1016/j.aeue.2021.153799.

[31] K.Sumathi, S. Lavadiya, P. Yin, J. Parmar, and S. K. Patel, "High gain multiband and frequency reconfigurable metamaterial superstrate microstrip patch antenna for $\mathrm{C} / \mathrm{X} / \mathrm{Ku}$ band wireless network applications," Wirel. Networks, Feb. 2021, doi: 10.1007/s11276021-02567-5.

[32] S. K. Patel and Y. Kosta, "Investigation on radiation improvement of corner truncated triband square microstrip patch antenna with double negative material," J. Electromagn. Waves Appl., vol. 27, no. 7, pp. 819-833, May 2013, doi: 10.1080/09205071.2013.789407.

[33] S. K. Patel, K. H. Shah, and Y. P. Kosta, "Frequency-reconfigurable and high-gain 
metamaterial microstrip-radiating structure," Waves in Random and Complex Media, vol. 29, no. 3, pp. 523-539, Jul. 2019, doi: 10.1080/17455030.2018.1452309.

[34] S. K. Patel, Y. P. Kosta, and S. Charola, "Liquid metamaterial based radome design," Microw. Opt. Technol. Lett., vol. 60, no. 9, pp. 2303-2309, Sep. 2018, doi: 10.1002/mop.31350.

[35] P. K. Li, Z. H. Shao, Q. Wang, and Y. J. Cheng, "Frequency- and pattern-reconfigurable antenna for multistandard wireless applications," IEEE Antennas Wirel. Propag. Lett., vol. 14, pp. 333-336, 2015, doi: 10.1109/LAWP.2014.2359196.

[36] Y. P. Selvam, L. Elumalai, M. G. N. Alsath, M. Kanagasabai, S. Subbaraj, and S. Kingsly, "Novel Frequency- A nd Pattern-Reconfigurable Rhombic Patch Antenna with Switchable Polarization," IEEE Antennas Wirel. Propag. Lett., vol. 16, pp. 1639-1642, 2017, doi: 10.1109/LAWP.2017.2660069.

[37] R. Dewan, M. K. A. Rahim, M. R. Hamid, M. Himdi, H. A. Majid, and N. A. Samsuri, "HIS-EBG unit cells for pattern and frequency reconfigurable dual band array antenna," Prog. Electromagn. Res. M, vol. 76, pp. 123-132, 2018, doi: 10.2528/PIERM18090202.

[38] L. Han, C. Wang, W. Zhang, R. Ma, and Q. Zeng, "Design of frequency- and patternreconfigurable wideband slot antenna," Int. J. Antennas Propag., vol. 2018, 2018, doi: $10.1155 / 2018 / 3678018$.

[39] G. Jin, M. Li, D. Liu, and G. Zeng, “A Simple Planar Pattern-Reconfigurable Antenna Based on Arc Dipoles," IEEE Antennas Wirel. Propag. Lett., vol. 17, no. 9, pp. 16641668, Sep. 2018, doi: 10.1109/LAWP.2018.2862624.

[40] B. Ashvanth, B. Partibane, M. G. Nabi Alsath, and R. Kalidoss, "Tunable dual band antenna with multipattern reconfiguration for vehicular applications," Int. J. RF Microw. Comput. Eng., vol. 29, no. 12, Dec. 2019, doi: 10.1002/mmce.21973. 